\title{
Bilateral sequential lung transplantation for end stage septic lung disease
}

\author{
A Hasan, P A Corris, M Healy, N Wrightson, A D Gascoigne, D A Waller, I Wilson, \\ C J Hilton, F K Gould, J Forty, J H Dark
}

\begin{abstract}
Background - Bilateral sequential lung transplantation (BSLT) has been widely adopted as an alternative to combined heart and lung transplantation for the management of end stage septic lung disease in many transplant centres.

Methods - A retrospective review was undertaken of the first 32 consecutive patients with septic lung disease to undergo BSLT at the Freeman Hospital.

Results - Between April 1988 and October 199432 patients underwent BSLT. Survival at 30 days was $85 \%$ and actuarial survival at one year was $70 \%$. Improved pulmonary function was seen in all surviving patients. Conclusion - BSLT for septic lung disease offers comparable survival to heart-lung transplantation, with excellent functional results. Long term results may be superior because the disadvantages of transplanting the heart are avoided.

(Thorax 1995;50:565-566)
\end{abstract}

Keywords: lung transplantation, cystic fibrosis.

Heart-lung transplantation, originally introduced for Eisenmenger's syndrome, ${ }^{1}$ has been successfully used for the treatment of septic lung disease with one year survival exceeding $70 \%$ and good functional results. ${ }^{2}$ This technique results in the unnecessary placing of a denervated donor heart in a patient with no cardiac dysfunction and who, as a result, is exposed to the risks of accelerated coronary artery disease, the incidence of which can be as high as $12 \%$. $^{3}$ Bilateral sequential lung transplantation (BSLT), with hilar anastomoses, retains the innervated heart and reduces the risks of vagal damage and excessive mediastinal bleeding, and has been successfully used in patients with septic lung disease. ${ }^{45}$

\section{Methods}

\section{PATIENT SELECTION}

150 patients with septic lung disease (119 with cystic fibrosis and 31 with other forms of bronchiectasis) were assessed for pulmonary transplantation between April 1988 and October 1994 at our institution. Patients were accepted for transplantation if they showed evidence of progressive respiratory failure with significant hypoxaemia and reduced exercise tolerance. The presence of multiresistant organisms (e.g. Pseudomonas cepacia) or bronchopulmonary aspergillosis did not preclude acceptance.

OPERATIVE TECHNIQUE

In our current technique the access is through a "clam shell" incision. Cardiopulmonary bypass is routinely used during implantation of the second lung and often during implantation of both lungs. The donor bronchus is kept very short and the suture line is covered with donor and recipient peribronchial tissues.

Standard triple immunosuppression therapy consisting of cyclosporin, azathioprine, and steroids is used, together with equine antihuman thymocyte globulin for the first three days.

\section{Results}

Between April 1988 and October 199432 patients (19 women) of mean age 29 years (range 15-49) with end stage septic lung disease underwent BSLT.

The 30 day survival was $85 \%$ (figure). The causes of early death were donor organ failure in one patient, bronchial dehiscence in one patient, and sepsis in three patients. Two of these patients developed mediastinitis and grew Staphylococcus aureus and Pseudomonas aeruginosa respectively; the third sepsis-related death was due to uncontrollable Pseudomonas cepacia infection in the lung and pleural spaces. Actuarial survival at six months and one year were $78 \%$ and $70 \%$, respectively. At two years the survival was $66 \%$. There have been seven late deaths. In five patients death followed the development of obliterative bronchiolitis and, in another two, sepsis led to multiorgan failure and death.

There were 25 episodes of infection that required treatment within six months of transplantation. Major infective complications were mediastinitis in two patients, septicaemia in four patients, and disseminated nocardial infection in one patient.

Lymphoproliferative disease was seen in one patient. Histological appearances were of high grade non-Hodgkin's lymphoma of B cell type consistent with an Epstein-Barr virus driven lymphoproliferative disorder.

There were 23 episodes of rejection (grade A2 and above) treated in 27 patients within six months of transplantation. Obliterative bronchiolitis was diagnosed by transbronchial biopsy in five patients. There was relentless deterioration in all these patients and death within six months of diagnosis despite treatment.

Airway complications were seen in only two patients; ischaemic stenosis of the intermediate bronchus was successfully treated with serial dilatation and stenting in one, and bronchial dehiscence occurred in another patient who subsequently died.

All survivors showed marked improvement in pulmonary function. Mean (SD) $\mathrm{PaO}_{2}$ measured on room air was $10.80(0.92) \mathrm{kPa}$ at one month after transplantation $(\mathrm{p}<0 \cdot 01)$ compared 


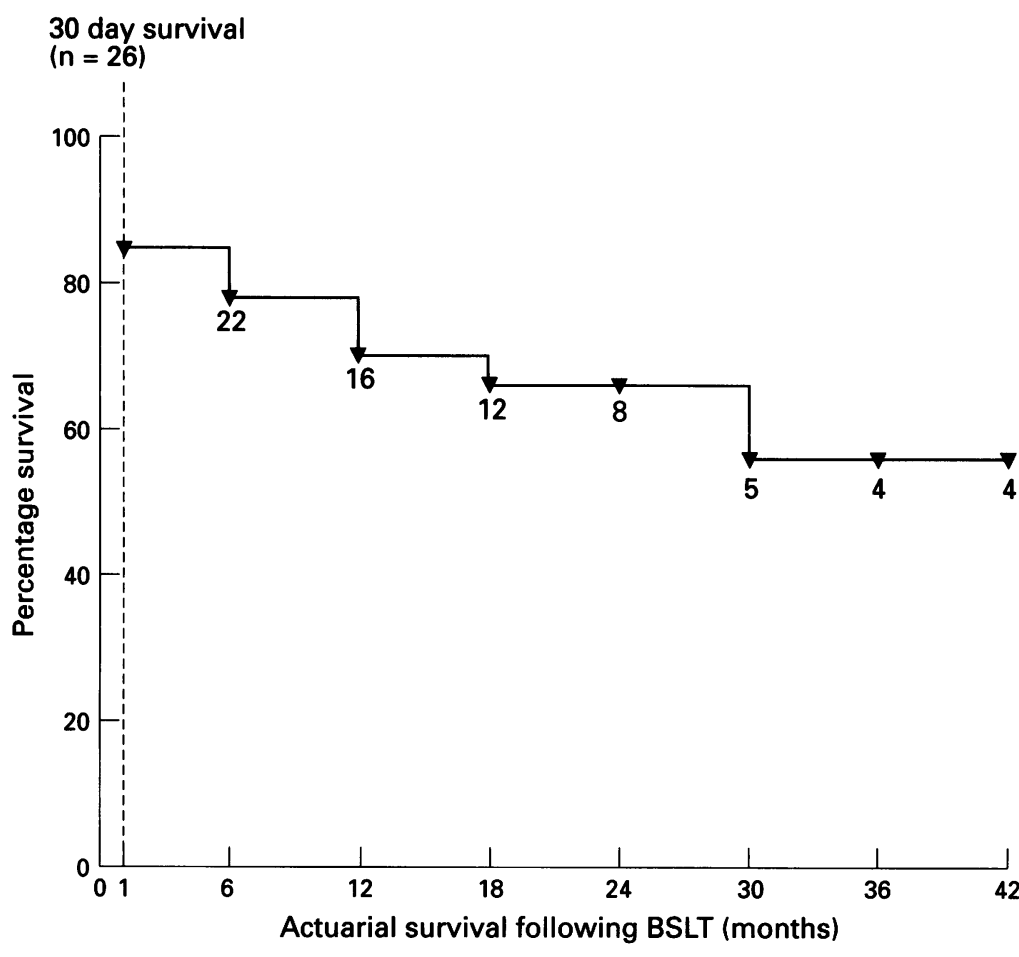

Actuarial survival of patients undergoing bilateral sequential lung transplantation (BSLT) for end stage septic lung disease. attribute this low incidence of airway complications to the routine use of high dose steroids early in the perioperative period with possible resultant increased bronchial blood flow. ${ }^{9}$

Rejection and infection occurred frequently during the first month after transplantation and gradually decreased over six months. Infective $\stackrel{\varpi}{x}$ complications were a major cause of mortality and morbidity during the first six months. Obliterative bronchiolitis remains a major problem in long term survivors following pulmonary $\frac{\bar{\sigma}}{\bar{N}}$ transplantation. ${ }^{10}$ Five of our long term sur- $\frac{\pi}{\widehat{D}}$ vivors have developed the condition and sub- $\stackrel{2}{2}$ sequently died due to progressive respiratory failure. Although some groups consider re- $\overrightarrow{0}$ transplantation for patients with end stage ob- $\overrightarrow{\vec{H}}$ literative bronchiolitis, we believe the present $\stackrel{\omega}{\sigma}$ results of this procedure do not justify such a $\underset{x}{\vec{x}}$ course of action. ${ }^{11}$

One potential advantage of BSLT over heart- of lung transplantation is the preservation of auto- of nomic cardiac innervation and possible func- of tional consequences of cardiac denervation. 은 Although Schaefers $e t$ al concluded that cardiac $\vec{z}$ denervation occurs after double lung transplantation, ${ }^{12}$ we have shown that autonomic pathways remain intact after BSLT. ${ }^{13}$ This is $\overrightarrow{\mathscr{C}}$ due to minimal mediastinal dissection inherent in the technique of BSLT.

In conclusion, BSLT has evolved to become the operation of choice for patients with end stage septic lung disease. It provides a good early and intermediate survival with excellent $\triangle$ functional results. Future challenges include $\overline{\overline{0}}$ the reduction of early morbidity and mortality from septic complications and prevention of the development of obliterative bronchiolitis.

Reitz BA, Wallwork J, Hunt SA, Pennock JL, Billingham ME, Oyer PE, et al. Heart-lung transplantation: successful $\overline{0}$ therapy for patients with pulmonary vascular disease. $N$ Engl f Med 1981;306:557-64.

2 Jones L, Higgenbottam T, Wallwork J. Successful heartlung transplantation for CF. Chest 1988;93:644-5.

3 Dawkins KD, Jamieson SW, Hunt SA, Baldwin JC, Burke $\mathrm{CM}$, Morris A, et al. Long-term results, haemodynamics, 음 and complications after combined heart and lung transplantation. Circulation 1985;71:919-26.

4 Ramirez JC, Patterson GA, Winton TL, de Hoyos AL, 을 Miller JD, Maurer JR. Bilateral lung transplantation for $\mathrm{N}$ cystic fibrosis. $\mathcal{F}$ Thorac Cardiovasc Surg 1992;10:287-94. G

5 Shennib H, Noirclerc M, Ernst P, Metras D, Mulder DS, Giudicelli $\mathrm{R}$, et al. Double-lung transplantation for cystic $\mathrm{N}$ fibrosis. Ann Thorac Surg 1992;54:27-32.

6 Forty J, Hasan A, Gould FK, Corris PA, Dark JH. Single C lung transplantation with simultaneous contralateral pneumonectomy for cystic fibrosis. $\mathcal{f}$ Heart Lung Transplant 1994;13:727-30.

7 Pasque MK, Cooper JD, Kaiser LR, Haydock DA, Triantafillou A, Trulock EP. Improved technique for bilateral lung transplantation: rationale and initial clinical ex- $T$ perience. Ann Thorac Surg 1990;49:785-91.

8 Sharples LD, Scott JP, Dennis C, Higgenbottam TW, Stew- O art $\mathrm{S}$, Wreghitt $\mathrm{T}$, et al. Risk factors for survival following combined heart-lung transplantation. Transplantation 1994;57:218-23.

9 Inui K, Schaefers JH, Aoki M, Becker V, Ongsiek B, Kemnitz $\mathrm{J}$, et al. Bronchial circulation after experimental lung transplantation. The effect of long-term administration of pred- $\Omega$ nisolone. $f$ Thorac Cardiovasc Surg 1993;105:474-8.

10 Burke CM, Glanville AR, Theodore J, Robin ED. Lung immunogenicity, rejection and obliterative bronchiolitis. immunogenicity, rejection and obliterative bronchiolitis. 을

11 Novick RJ, Kaye MP, Patterson GA, Andrèassian B, Klepetko W, Menkis AH, et al. Redo lung transplantation: a North American-European experience. $\mathcal{F}$ Heart Lung Transplant 1993;12:5-16.

12 Schaefers HJ, Waxman MB, Patterson GA, Frost AE, Maurer J, Cooper JD, et al. Cardiac innervation after double lung transplantation. $\mathcal{f}$ Thorac Cardiovasc Surg 1990;99:22-9.

13 Morgan-Hughes NJ, Corris PA, Healey MD, Dark JH, McComb JM. Cardiovascular and respiratory effects of adenosine in man after pulmonary denervation. $₹ A$ Apl Physiol 1994;76:756-9. 